\title{
Celebrating Biogeochemistry: over 35 years of publication
}

\author{
Sujay Kaushal $\cdot$ Robert Howarth $\cdot$ Kate Lajtha
}

Received: 5 May 2021 / Accepted: 8 May 2021/Published online: 31 May 2021

(C) The Author(s), under exclusive licence to Springer Nature Switzerland AG 2021

This special anniversary issue celebrates over 35 years of publication of the journal, Biogeochemistry. To our knowledge, Biogeochemistry is the first core journal devoted exclusively to the rapidly growing field of biogeochemistry. Since its inception, the journal has allowed many thousands of authors from different countries to communicate the growing scope, concepts, and themes of biogeochemistry. The journal has also made these research findings and perspectives accessible to global audiences and multiple generations of researchers, educators, students, environmental managers, and more. In particular, the journal has also created a unique and special home for papers analyzing the geochemistry of the Earth's surface influenced by biological processes and human activities. Before the publication of Biogeochemistry, papers were sometimes rejected by journals for either being "too biological" or too "geochemical" in content. Since its inception, the journal has aimed to fill this important gap and builds bridges between earth

S. Kaushal ( $\square)$

University of Maryland, College Park, MD, USA

e-mail: skaushal@umd.edu

R. Howarth

Cornell University, Ithaca, NY, USA

K. Lajtha

Oregon State University, Corvallis, OR, USA and life sciences and has fostered interdisciplinary work related to Earth's elemental cycles over more than 35 years.

Over the history of the journal, there have only been two editors-in-chief of Biogeochemistry, Robert Howarth and Kate Lajtha. The journal was originally published by Dr. W. Junk Co. and conceived by Ad Plazier (a former graduate student in soil science from the Netherlands who was hired by the small publishing firm of Dr. W. Junk to explore a new interdisciplinary journal). Howarth was only four years out of his Ph.D. when accepting the critical role as the founding editor of the journal. Kate Lajtha then accepted the role of successfully growing the journal to present day, after serving as co-editor-in-chief for a few years, taking over the helm completely in 2004. In addition to only two editors-in-chief, Biogeochemistry has only had a few publishers since its inception. This remarkable level of stability and continuity has allowed the journal to build a strong community of both experienced and new editors and readers spanning generations. Since the journal's start, the editors-in-chief have chosen associate editors and editorial boards that have encompassed geographic diversity, as well as a mix of aquatic and terrestrial biogeochemists who work on different elemental cycles. The stable history of editors-in-chief has allowed pursuing innovative publishing ideas, particularly the publication of numerous special issues. In fact, the very first published issue of Biogeochemistry in 1984 was a special issue based 
talks organized by the International SCOPE Sulphur Program and presented at a meeting of the Ecological Society of America. Since the publication of its first research article (Howarth 1984), some of the most highly-cited and influential papers in the field of biogeochemistry have been published in our special issues and/or have been specially invited and/or solicited by our editors. We continue this tradition, and encourage all readers and potential authors to approach us, if they have a special issue or editorial/ publishing idea in mind that can help serve our growing scientific community.

Over the past four decades, Biogeochemistry has also risen in impact factor and diversified the types of published articles and perspectives. Articles now include a combination of traditional papers, emerging ideas and syntheses, biogeochemistry letters, and editorials (Lajtha 2017). The journal has grown and thrived despite constant competition from the emergence of subsequent related journals and open access publishing fees. Upon the advice and guidance of Ad Plaizier, the journal published issues on time from the very start, even if that meant publishing an issue with only two or three papers. This was nerve wracking for the editor-in-chief, but was also essential to build momentum and confidence among potential authors. Those fledgling origins and the continued dedication of the editors, authors, and reviewers has allowed the journal to become a key component of our field. As the field of biogeochemistry matured, both the scope and the format of Biogeochemistry grew and expanded over the past 35 years. Biogeochemistry now hosts two special sections, Biogeochemistry Letters and Synthesis and Emerging Ideas, and established two separate review boards including one that serves to mentor emerging scholars in the field.

In this special issue, we celebrate over 35 years of Biogeochemistry and its growth and evolution in the scientific record of the earth and life sciences. We include papers on diverse themes and topics across biomes and issues of past, current, and future interest to our readership. These papers explore the evolution of biogeochemistry as a discipline and modern perspectives on the biogeochemistry of: temperate and tropical forests, soil carbon and nutrient cycling, agricultural systems, regional and global elemental cycles, freshwaters, salinization, coastal zones, marine environments, and more. This special issue attempts to illustrate the wide ranging scope of Biogeochemistry and its ongoing and evolving role in exploring and investigating past, present, and future changes in Earth's elemental cycles and integrating and transforming earth and life sciences. Not all fields of biogeochemistry can be represented within the pages of one single special issue, and we encourage you to peruse through volumes in the past, present, and future to appreciate the full scope and impact of the journal.

We thank our numerous editorial boards, authors, and reviewers over almost four decades of publication-without them, none of this would be possible. Of particular significance, creation and publication of this particular special issue coincided with a global pandemic and other difficult times. We are grateful for our dedicated contributors, reviewers, and readership to make this special celebration issue possible (and enjoyable) despite these challenges.

Kind Regards,

Sujay Kaushal (Associate Editor), Robert Howarth (Founding Editor), and Kate Lajtha (Editor-in-Chief).

\section{Reference}

Howarth RW (1984) The ecological significance of sulfur in the energy dynamics of salt marsh and marine sediments. Biogeochemistry 1(1):5-27

Lajtha K (2017) Brave new world. Biogeochemistry. https://doi. org/10.1007/s10533-017-0316-y

Publisher's Note Springer Nature remains neutral with regard to jurisdictional claims in published maps and institutional affiliations. 